\title{
Feeding ecology of silver hake larvae on the Western Bank, Scotian Shelf, and comparison with Atlantic Cod
}

\author{
C. Reiss*†, I. McLarent, P. Avendañoł And C. Taggart* \\ *Department of Oceanography, Dalhousie University, Halifax, Nova Scotia, B3H 4J1, \\ Canada and $\$$ Department of Biology, Dalhousie University, Halifax, Nova Scotia, \\ B3H 4J1, Canada
}

(Received 27 January 2004, Accepted 15 November 2004)

\begin{abstract}
The feeding ecology of the larvae of silver hake Merluccius bilinearis was examined during two time periods (October 1998 and December 1992) on the Western Bank, Scotian Shelf, northwest Atlantic, and compared with the feeding ecology of Atlantic cod Gadus morhua larvae collected in the same samples in December 1992. During both time periods silver hake exhibited strong selection for late stage copepodids and adult copepods at a small size $(>3.5 \mathrm{~mm}$ total length, $\left.L_{\mathrm{T}}\right)$. The niche width measured as the diet breadth index $\left(I_{\mathrm{DB}}\right)$ of silver hake declined rapidly as they increased in size and remained relatively constant from 3 to $11 \mathrm{~mm} L_{\mathrm{T}}$, during each time period. Atlantic cod larvae exhibited a broader niche width that was curvilinear over the same $L_{\mathrm{T}}$. Atlantic cod were also less selective than silver hake, incorporating both naupliar and early stage copepodids in their diets throughout the length classes examined. Simple isometric relationships did not explain the differences in diet, as Atlantic cod larvae continued to feed on early stages of copepods at large size, while silver hake larvae quickly switched to large prey items. The strong selection and narrow $I_{\mathrm{DB}}$ observed for silver hake probably reflects adaptation to spawning during the periods between major secondary production peaks in temperate waters. (C) 2005 The Fisheries Society of the British Isles (No claim to original US government works)
\end{abstract}

Key words: Atlantic cod; feeding ecology; Scotian shelf; selectivity; silver hake.

\section{INTRODUCTION}

The understanding of the feeding ecology of larval fishes is critical to assessing the mechanisms responsible for the success or failure of cohorts, and potentially year class strength of marine fish populations (Cushing, 1990). Given the prevailing view that larval fishes in marine environments are food-limited (Hunt von Herbing \& Gallager, 2000; Hinrichsen et al., 2003), larval fishes should exhibit feeding patterns that maximize energy intake (Werner \& Hall, 1974). Fish larvae are visual predators, so the number and types of prey consumed will also reflect the ease of capture (McLaren \& Avendaño, 1995), the apparent size (Luo et al., 1996) or presentation of food items (Fiksen et al., 1998; Reiss et al., 2002) to the individual, thereby describing the selectivity for

$\uparrow$ Author to whom correspondence should be addressed at present address: Southwest Fisheries Science Center, 8604 La Jolla Shores Drive, La Jolla, 92037, U.S.A. Tel.: +1 8585467127 ; fax: +1 8585465614 ; email: christian.reiss@noaa.gov 
prey by a species. Pearre (1986) has suggested that the niche width of a species (measured as the S.D. of the $\log _{10}$ of prey size) should remain constant with length, as smaller food items are replaced by larger items during growth and development, thereby maximizing energy intake. Additionally, the selectivity exhibited by an individual should change given the prey concentration, distribution and abundance by declining in predictable or food-rich environments (Mayer \& Wahl, 1997; Munk, 1997).

Many early life-history studies have focused on testing the generality of the hypothesis that the feeding-niche width remains constant with increasing fish size (jaw or body length) in order to maximize energy gain (Pearre, 1986; Hilgruber et al., 1997; Munk, 1997; Pepin \& Penney, 1997, 2000; GonzalezQuiros \& Anadon, 2001). Yet the results of these studies are mixed, and authors have found increasing, constant or non-linear relationships between feedingniche width and fish size. Fewer studies have examined whether perceived selectivity changes under different prey concentrations and distributions.

In this study, the feeding ecology of the larvae of silver hake Merluccius bilinearis (Mitchill) on the Western Bank, Scotian Shelf was examined and the results related to predictions from feeding theory (Shirota, 1970; Pearre, 1986; Pepin \& Penney, 1997) by comparing and contrasting the feeding ecologies of larval silver hake and larval Atlantic cod Gadus morhua L., which occurred with the silver hake, during two time periods, October 1998 and December 1992. The hypothesis was also tested that temporal patterns of prey ingestion and niche width reflected differences in relative abundance of prey taxa and sizes available before (October) and after (December) the autumn plankton bloom, and that selectivity decreased at the end of the spawning season of silver hake (Werner \& Hall, 1974; Bartell, 1982; Jeffrey \& Taggart, 2000).

\section{MATERIALS AND METHODS}

\section{PLANKTON COLLECTIONS}

Zooplankton and larval fishes used in the present study were derived from three series of collections on and around the Western Bank, Scotian Shelf (Fig. 1). One series was collected during cruise 9858 from 29 September to 15 October 1998 as part of the Canadian GLOBEC (Global Ecosystem Dynamics) programme. The second series of collections was obtained during cruises conducted in support of the Ocean Production Enhancement Network (OPEN) programme conducted over and around the Western Bank between 1991 and 1993. In particular, samples were collected during the OPEN cruise 9231 in November and December 1992. Some of the Atlantic cod data used here were previously used in a different form by McLaren et al. (1997) to relate feeding success to oceanographic features. In the present study the data underwent a new analysis, as they specifically related to selectivity and niche width of silver hake. Finally, some measurements (120) of the lower jaw length of Atlantic cod larvae were from samples collected during the OPEN cruise 9103 conducted in May 1991 on the Western Bank.

Details of the sampling strategies for each cruise are given elsewhere (Taggart et al., 1996; McLaren et al., 1997; Reiss et al., 2002, 2003). Briefly, larval fishes were collected at vertically discrete depths using a $1 \mathrm{~m}^{2}$ BIONESS net equipped with nine nets of $333 \mu \mathrm{m}$ mesh. Samples were collected at c. $3 \mathrm{~h}$ intervals over a 23 day period (OPEN cruises 9231; 9103); and at a variety of times of the day and night over a 20 day period, as well as over a $36 \mathrm{~h}$ period during the Canadian GLOBEC cruise 9858. Larval fish abundance estimates were expressed as a concentration (number $100 \mathrm{~m}^{-3}$ ). 


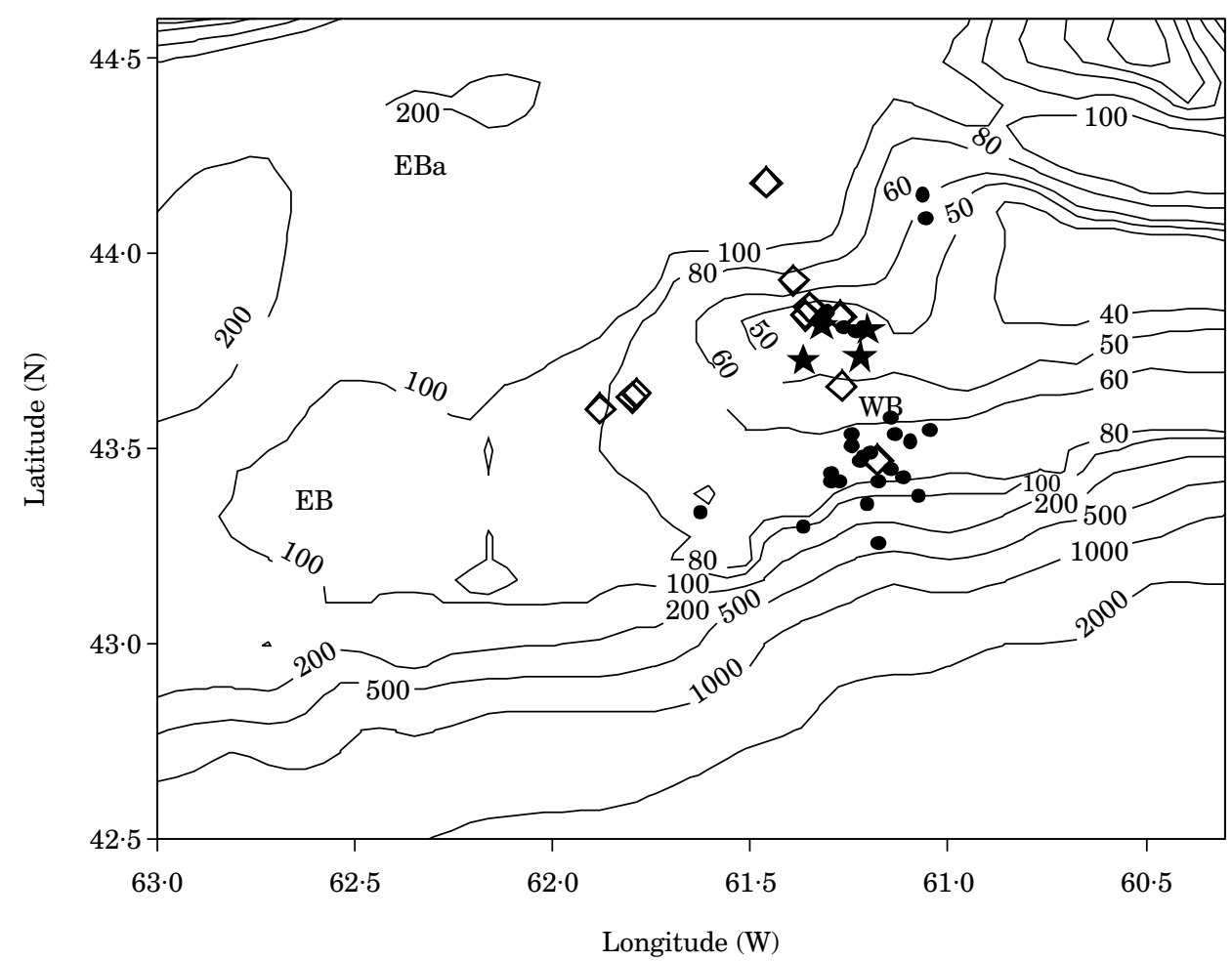

FIG. 1. Bathymetric chart of the Western Bank showing locations of BIONESS and vertical net samples collected during cruise 9858 in October $1998(\diamond)$ and cruise 9231 in December $1992(\star, \bullet)$. WB, Western Bank; EB, Emerald Bank; EBa, Emerald Basin.

The vertical distribution of zooplankton was also determined during these two cruise periods. During November 1998, a closing ring-net, $50 \mathrm{~cm}$ in diameter with $64 \mu \mathrm{m}$ mesh equipped with a mechanical flowmeter was used to sample three to six depth strata at each station, including the mixed layer, a pycnocline layer and sub-pycnocline waters. At some stations, samples were collected from five nominal depth strata $0-7,7-14,14-21$, 21-28 and $28-35 \mathrm{~m}$, at $c .3 \mathrm{~h}$ intervals using the closing $64 \mu \mathrm{m}$ plankton net. Further, smaller zooplankton size classes were sampled concurrently with the bongo samples using an attached $25 \mathrm{~cm}$ diameter net with $64 \mu \mathrm{m}$ mesh. During November 1992, the vertical distribution of zooplankton was determined at four stations near the crest of the Western Bank (McLaren \& Avendaño, 1995) and four discrete depths (5, 15, 25 and $35 \mathrm{~m}$ ) using a $25 \mathrm{~cm}$ Clarke-Bumpus sampler equipped with $64 \mu \mathrm{m}$ mesh nets. Because depth, or other associated variables may contribute to perceptions of feeding selectivity and niche width, the zooplankton and larval fish data were pooled into four depth zones $(0-10,10-20,20$ 30 and $>30 \mathrm{~m}$ ) in order to ensure adequate numbers of fishes of a variety of sizes were available for subsequent analyses. Preliminary analyses of the depth discrete samples as described below did not show any large differences as compared to the pooled data, so niche widths and selectivity indices are shown for the overall pooled data.

\section{LABORATORY ANALYSIS}

Fish larvae were removed from all plankton samples, identified to species, enumerated and measured (total length, $L_{\mathrm{T}}$, to the nearest $0 \cdot 1 \mathrm{~mm}$ ) under magnification using a video 
camera and SigmaScan Pro (Ver 5.0.0, SPSS, Inc. 1999) or using an ocular micrometer under magnification. No correction for shrinkage was made.

Samples preserved in formalin (37\% formaldehyde) from the $64 \mu \mathrm{m}$ mesh nets were used to enumerate copepod eggs, nauplii, copepodids and adults, as well as other invertebrate taxa. The fine-mesh $(64 \mu \mathrm{m})$ samples were sub-sampled by a Folsom plankton splitter, and eggs, nauplii, copepodid and adult copepods were identified and enumerated to species and developmental stage mainly from Lawson \& Grice (1970), Diaz \& Evans (1983), Sazhina (1985) and Frost (1989), or to lowest possible taxonomic category. Other well-known planktonic taxa were identified to genera from a variety of sources. Abundance of copepods and other zooplankton was expressed as concentration (number $\mathrm{m}^{-3}$ ).

\section{FEEDING SUCCESS}

Larval fishes used for gut content analysis were randomly selected from each of the formalin-preserved BIONESS samples in proportion to their concentration among collections (as many as 30 fish per sample) for a total of 837 silver hake larvae in 1998. On average, 16 fish were examined (range one to 30) per sample. Historical gut content data for 683 Atlantic cod larvae collected during November to December 1992 were obtained from databases, and 227 silver hake larvae were removed from preserved samples collected at the same stations, and their guts examined for prey items. The samples were restricted to those collected between 0800 and 2400 hours. Stomach contents of all larval fishes were examined under magnification, identified and enumerated according to the method of McLaren \& Avendaño (1995). The gut was excised and opened using PrecisionGlide ${ }^{\circledR}$ $27 \mathrm{G}^{1 / 2}$ needle or a $2 \cdot 5 \mathrm{Mrad}$. Feather ${ }^{\mathrm{B}}$ scalpel. Each food item was identified to the lowest possible taxonomic level and developmental stage and the item was measured. Where possible, the length and width of both the prosome and metasome of late stage copepods was measured. The shape of nauplii, however, differs, so a third measurement was made corresponding to the narrowest part of the body that in copepodid stages would form the posterior portion of the metasome and urosome. Lengths and widths of individual prey items were determined to $0 \cdot 1 \mathrm{~mm}$ using a calibrated ocular micrometer.

A number of measurements (all in $\mathrm{mm}$ ) were made on each larva, including body depth, gut length, depth and height (these measurements were necessary to properly calculate the gut volume), and the length of the lower jaw, an index of maximum mouth gape. Previous feeding studies on silver hake and Atlantic cod have shown that body length was highly correlated $\left(r^{2}>0 \cdot 9\right)$ with mouth width (Sumida \& Moser, 1980; Kane, 1984). Additionally, maxillary length (lower jaw) was also highly correlated with $L_{\mathrm{T}}$. Given these findings, in this study the lower jaw length was used as an index of mouth gape, and therefore as an index of the ability of each species to feed on prey of a given size.

\section{DATA ANALYSES}

The feeding-niche width was calculated for each species and time period using Pearre's (1986) diet breadth index, $I_{\mathrm{DB}}$, which is defined here as the s.D. of the $\log _{10}$ of the prey length in individual guts. Only larvae with three or more prey items in their gut were used. Pearre (1986) has suggested that this index is independent of prey size, and has suggested that the diet breadth should be independent of size. Chesson's (1978) index of prey selection was also used to determine the relative selectivity of prey types by Atlantic cod and silver hake larvae collected in the same samples during 1992 and the patterns were compared to those observed for silver hake (Atlantic cod were not found in 1998) during 1998, by size class $(<3,3-5,5-7,7-$ 9, 9-11 and $>11 \mathrm{~mm} L_{\mathrm{T}}$ ). Chesson's (1978) index was calculated as: $P_{i}=\left(a_{i} n_{i}^{-1}\right)\left[\left(\sum a_{i} n_{i}^{-1}\right)(i=1 \ldots m)\right]^{-1}$, where $a_{i}$ and $n_{i}$ are the proportions of prey items of each type $(i)$ in the stomachs and in the environment, and $m$ are the number of prey types (Chesson, 1978). Selection for 16 developmental classes of prey that roughly corresponded to size [eggs, nauplii 1-6, copepodids 1-5 and adults (males 
and females) of the copepods, and for Limacina spp., and Placopecten sp.] was examined. Chesson's (1978) index is lower-bounded, and neutral selection is defined as $m^{-1}$ of developmental or size classes considered.

Previous studies on the Western Bank have shown that time of day is an important factor contributing to variability in the gut contents of Atlantic cod (McLaren \& Avendaño, 1995; McLaren et al., 1997) and silver hake (Coates-Markle, 1982), potentially complicating inferences about feeding preference. To directly compare the diel patterns in feeding between silver hake and Atlantic cod, data from the 1992 cruises were pooled into six $4 \mathrm{~h}$ periods between 0800 and 0000 hours. The mean prey per gut and mean prey size by time of day pooled across size for each species were pooled for comparison.

\section{RESULTS}

\section{BODY AND MOUTH SIZE RELATIONSHIPS}

Silver hake larvae collected during 1992 and 1998 ranged from 2.5 to $35 \cdot 0$ and 2.5 to $20.0 \mathrm{~mm} L_{\mathrm{T}}$, respectively. Atlantic cod larvae ranged from $2 \cdot 1$ to $25.0 \mathrm{~mm} L_{\mathrm{T}}$. Linear regressions explained between 95 and $97 \%$ of the variability in jaw length, and the relationships between lower jaw and $L_{\mathrm{T}}$ differed between silver hake and Atlantic cod (Table I). No difference in this isometric relationship was found between years for silver hake. Atlantic cod had smaller jaws at a given size than silver hake. In addition, the jaw length of silver hake larvae increased at a faster rate than Atlantic cod. Thus, at any given size silver hake larvae could potentially consume larger prey items than Atlantic cod larvae of a similar $L_{\mathrm{T}}$. For example, Atlantic cod larvae would need to be between 5 and $7 \mathrm{~mm} L_{\mathrm{T}}$ to have the lower jaw length of 3 to $5 \mathrm{~mm}$ $L_{\mathrm{T}}$ silver hake larvae.

\section{WATER COLUMN PREY ABUNDANCE}

Considerable differences in the average prey abundances were observed between the two cruise periods (Table II). For example, Pseudocalanus parvus abundances were lower in December 1992 than in October 1998. Nauplii of $P$. parvus ranged from 17 to $294 \mathrm{~m}^{-3}$ in 1998 and copepodids ranged from 3 to $573 \mathrm{~m}^{-3}$. In December 1992, the mean abundance of naupliar stages of $P$. parvus ranged from 0 to $25 \mathrm{~m}^{-3}$, while copepodids ranged 6 to $107 \mathrm{~m}^{-3}$.

TABLE I. Relationship between lower jaw length $(y, \mathrm{~mm})$ and total length $(x, \mathrm{~mm})$ of silver hake collected in October 1998 and November 1992 and Atlantic cod collected in November 1992 on and around Western Bank, Scotian Shelf. Values in parentheses are S.E. of the coefficent estimates

\begin{tabular}{llll}
\hline & $n$ & \multicolumn{1}{c}{ Equation } & $r^{2}$ \\
\hline Silver hake 1992 & 227 & $y=0 \cdot 026(0 \cdot 020)+0 \cdot 1822(0 \cdot 002) x$ & 0.95 \\
Silver hake 1998 & 877 & $y=-0 \cdot 062(0 \cdot 008)+0 \cdot 1878(0 \cdot 001) x$ & 0.96 \\
Atlantic cod 1992 & 120 & $y=0 \cdot 004(0 \cdot 03)+0 \cdot 1318(0 \cdot 002) x$ & $0 \cdot 97$ \\
\hline
\end{tabular}




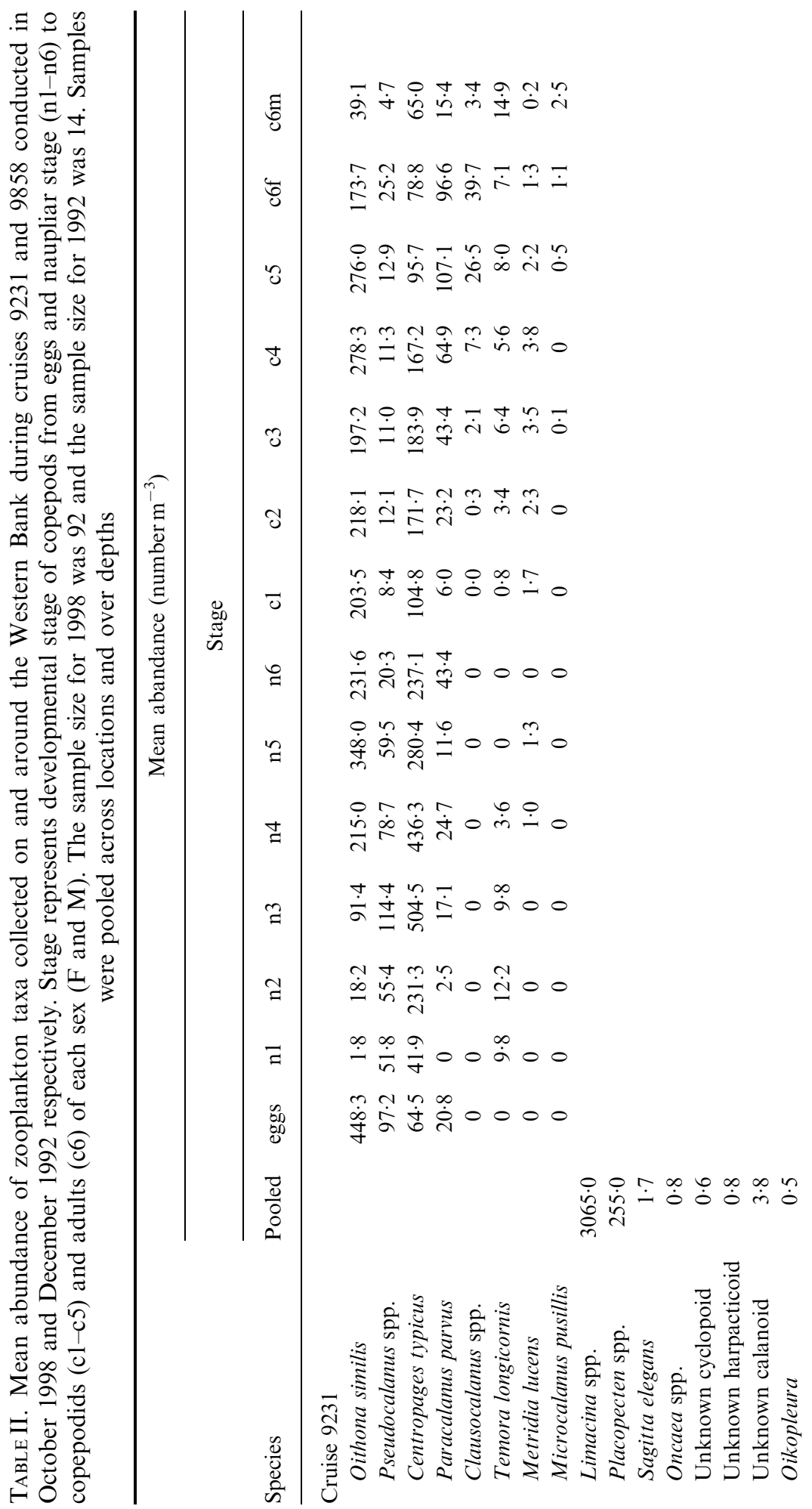




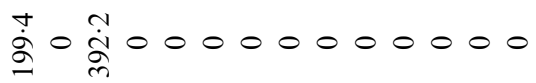

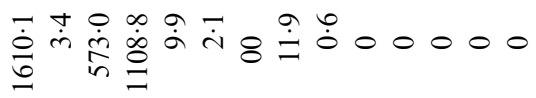

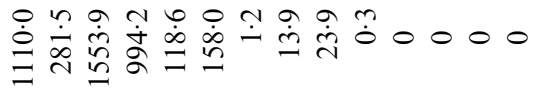

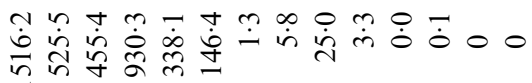

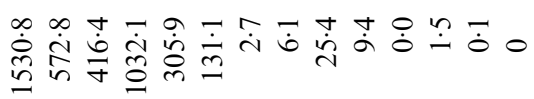

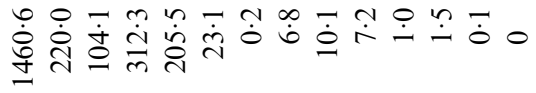

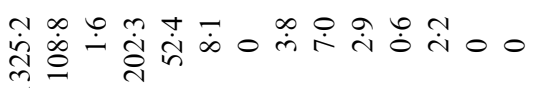

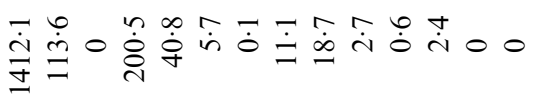

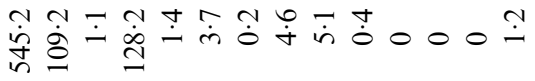

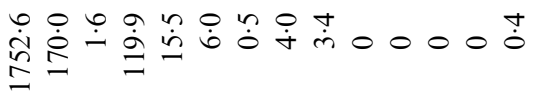

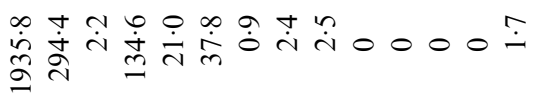

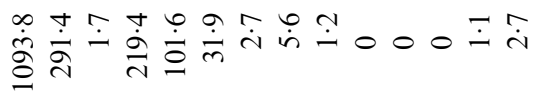

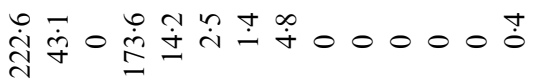

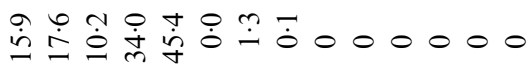

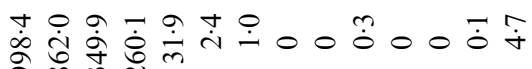

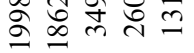

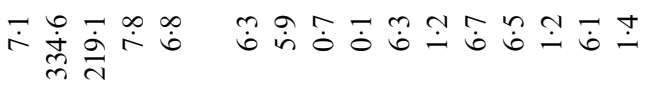

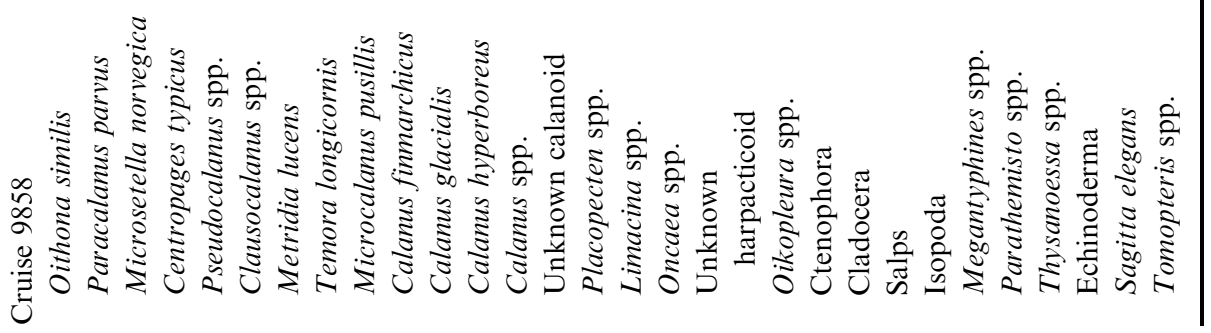


Such a pattern is consistent with the seasonal decline in many species following the autumn plankton bloom. In contrast, the mean abundance of naupliar stages of Pseudocalanus spp. ranged between 1.4 and $45 \mathrm{~m}^{-3}$ in October 1998, and were higher (between 20 and $97 \mathrm{~m}^{-3}$ ) in December 1992, while copepodids ranged between 90 and $338 \mathrm{~m}^{-3}$ in 1998 and 4 to $25 \mathrm{~m}^{-3}$ in 1992. The variability in mean concentration of prey items would suggest that considerable variability in the diet of silver hake should be expected between the two time periods.

The vertical distributions of developmental stages of copepods showed differences between cruises when pooled into four broad depth strata (Fig. 2.). In October 1998 copepodid and adult stages of copepods increased from the surface with depth, while nauplii exhibited a more uniform distribution across depth zones. In December 1992, all stages had essentially uniform vertical distributions, although there was some variability that reflected low sample sizes $(n<4)$.

\section{PREY COMPOSITION IN DIETS}

For both Atlantic cod and silver hake, four prey taxa comprised $>90 \%$ of the items in the diets (Table III). Pseudocalanus spp. and Centropages typicus made up most items in the diets of Atlantic cod ( $>80 \%)$, with fewer Limacina spp. and Oithona similis. Paracalanus parvus was a minor component of the diet $(>1 \%)$. The same four copepod taxa dominated the diet of silver hake. During autumn 1998, silver hake ate mostly P. parvus and C. typicus (>75\%), with smaller contributions of Clausocalanus spp. (12\%), and Pseudocalanus spp.

\section{Abundance (number $\mathrm{m}^{-3}$ )}
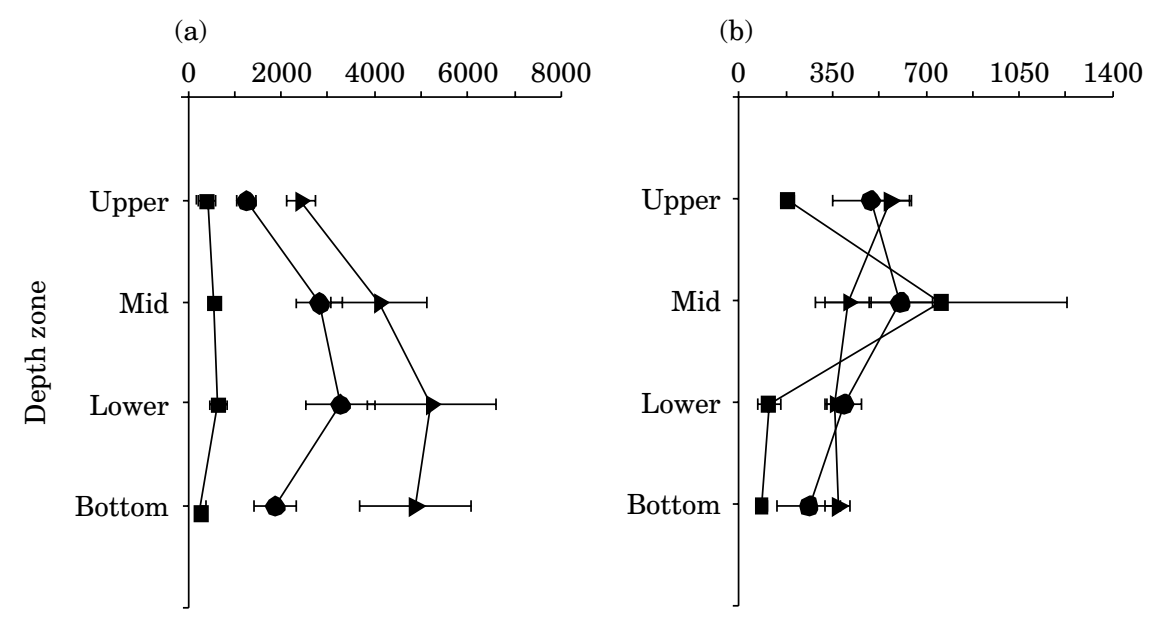

FIG. 2. Mean \pm 2 s.E. vertical distribution of the abundance for three developmental stages [n2 and c6f $(\boldsymbol{\Delta})$, see Table II] of copepods collected during (a) 1992 and (b) 1998. Note the difference in the $x$ axis between (a) and (b). 
TABLE III. Number and per cent occurrence of prey species in the diets of silver hake in 1992 and 1998 and Atlantic cod collected during 1992

\begin{tabular}{|c|c|c|c|c|c|c|}
\hline \multirow[b]{2}{*}{ Prey species } & \multicolumn{2}{|c|}{ Silver hake 1992} & \multicolumn{2}{|c|}{ Silver hake 1998} & \multicolumn{2}{|c|}{ Atlantic cod 1992} \\
\hline & $n$ & $\%$ & $n$ & $\%$ & $n$ & $\%$ \\
\hline Amphipod & 0 & 0 & 6 & $<1$ & 0 & 0 \\
\hline Calanus spp. & 18 & 1 & 89 & 2 & 30 & $<1$ \\
\hline Clausocalanus spp. & 621 & 43 & 497 & 12 & 14 & $<1$ \\
\hline Centropages typicus & 102 & 7 & 848 & 20 & 2346 & 25 \\
\hline Decapoda & 0 & 0 & 0 & 0 & 1 & $<1$ \\
\hline Euphausiid & 0 & 0 & 4 & $<1$ & 0 & 0 \\
\hline Eurytemora & 0 & 0 & 4 & $<1$ & 0 & 0 \\
\hline Fish larvae & 1 & $<1$ & 1 & $<1$ & 0 & 0 \\
\hline Limacina & 0 & 0 & 1 & $<1$ & 690 & 7 \\
\hline Microcalanus pusillus & 0 & 0 & 0 & 0 & 1 & $<1$ \\
\hline Microsetella norvegica & 0 & 0 & 0 & 0 & 9 & $<1$ \\
\hline Metridia longa & 0 & 0 & 0 & 0 & 2 & $<1$ \\
\hline Metridia lucens & 1 & $<1$ & 0 & 0 & 125 & 1 \\
\hline Oithona similis & 42 & 3 & 57 & 1 & 511 & 6 \\
\hline Paracalanus parvus & 380 & 27 & 2233 & 54 & 118 & 1 \\
\hline Placopecten magellanicus & 0 & 0 & 0 & 0 & 30 & $<1$ \\
\hline Polychaete & 0 & 0 & 1 & $<1$ & 0 & 0 \\
\hline Pseudocalanus spp. & 239 & 17 & 220 & 5 & 5305 & 58 \\
\hline Temora & 5 & $<1$ & 2 & $<1$ & 21 & $<1$ \\
\hline Tintinid & 0 & 0 & 5 & $<1$ & 0 & 0 \\
\hline Calanoidea & 4 & $<1$ & 3 & $<1$ & 5 & $<1$ \\
\hline Unknown & 0 & 0 & 1 & $<1$ & 3 & $<1$ \\
\hline Empty guts & 9 & 1 & 0 & 0 & 9 & $<1$ \\
\hline Debris & 0 & 0 & 11 & $<1$ & 0 & 0 \\
\hline
\end{tabular}

(5\%). In winter 1992, Clausocalanus sp. (>45\%) was the dominant food item followed by P. parvus $(>25 \%)$ and while Pseudocalanus spp. formed a larger percentage (c. 17\%) of the diets of silver hake, C. typicus declined in occurrence from $20 \%$ in October to just $7 \%$ in December. During autumn and winter Limacina sp. was also prominent in the diet of silver hake.

\section{DIEL FEEDING PATTERNS}

The number of prey per gut varied by time of day, and silver hake larvae had fewer prey in their guts than Atlantic cod at all hours of the day (Fig. 3). During 1992, both Atlantic cod and silver hake larvae had the most prey items in their guts during the crepuscular period between 1600 and 2000 hours. In 1998 silver hake had the highest numbers of prey items in guts between 2000 and 0000 hours.

On average, Atlantic cod and silver hake consumed prey of different sizes, and silver hake consumed larger prey than Atlantic cod. Mean size of prey of 
(a)

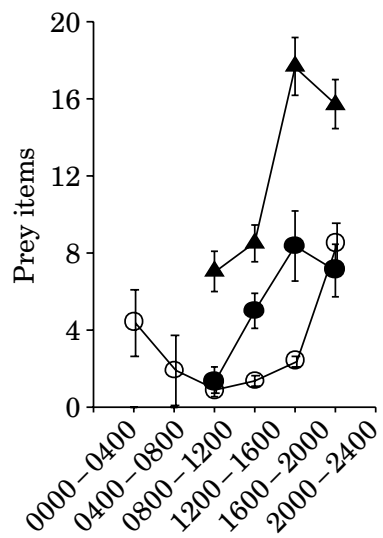

(b)

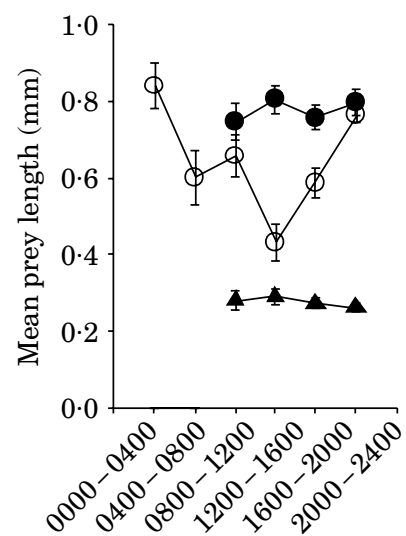

Time of day (hours)

FIG. 3. Diel variability in (a) the number and (b) size of prey in the guts of silver hake in 1992 (๑) and $1998(\bigcirc)$ and Atlantic cod in $1992(\mathbf{A})$. All sizes of larvae were combined and samples were pooled into six $4 \mathrm{~h}$ groups between 0800 and 0000 hours over the course of each cruise. Values are means \pm 2 s.e.

both silver hake and Atlantic cod larvae in 1992 increased during the afternoon period. In 1998, silver hake showed the opposite pattern, with a substantial decrease in mean prey size in the afternoon. Overall, however, the mean size of prey consumed by silver hake was much larger than that of Atlantic cod. Thus, while there was some evidence of changes in the size of prey eaten with time of day in 1998, the patterns were not consistent between time periods.

\section{ONTOGENETIC CHANGES IN DIET}

Both silver hake and Atlantic cod larvae exhibited significant positive relationships between body size and both the number and mean size of prey items ingested (Fig. 4 and Table IV). Overall there was considerable scatter in the data, and strong relationships were not observed when data collected over all times of the day were pooled. The correlation between prey size and $L_{\mathrm{T}}$, however, increased for both species when the data were restricted to the evening hours, when guts should have been fullest, but the increase was smaller for Atlantic cod than for silver hake. The correlation between the number of prey items in the gut and $L_{\mathrm{T}}$ increased substantially for silver hake larvae in the evening hours. In contrast, the correlation remained very low for Atlantic cod larvae at all times of night and day. Overall feeding success (number of fish with at least one prey item) was high for both species, with food present in guts of between 95 and 100\% for larvae of all sizes and for each species, between 0800 and 0000 hours.

As they grew, silver hake larvae switched from small to large prey at a relatively small size during both 1992 and 1998 (Fig. 4). In October 1998, prey 
(a)

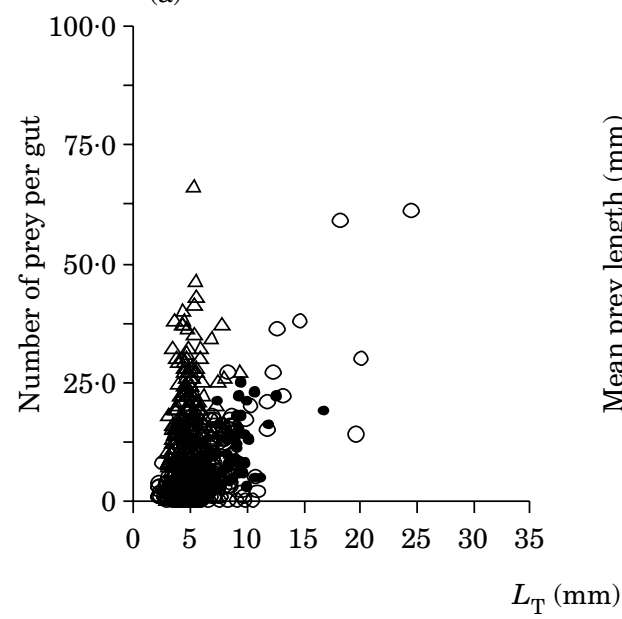

(b)

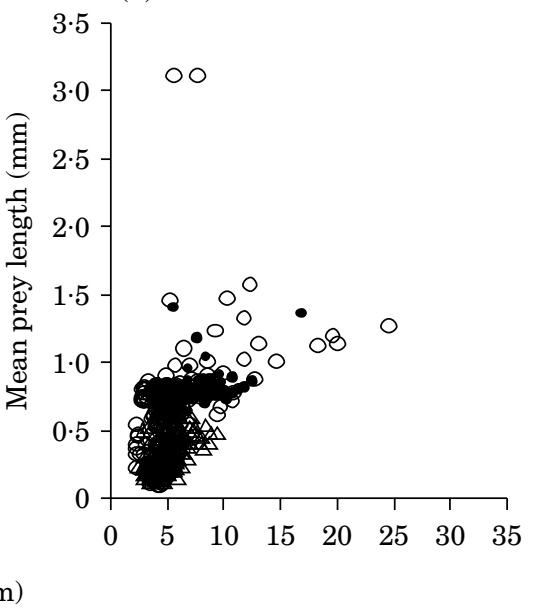

FIG. 4. Scatter plots of (a) the number and (b) mean size of prey in the guts in relation to total length of silver hake during $1992(\bullet)$ and $1998(\bigcirc)$ and Atlantic cod $(\triangle)$ in 1992, collected between 0800 and 0000 hours. A random selection of $50 \%$ of the data is presented.

consumed by the smallest silver hake larvae $(<3.5 \mathrm{~mm})$ were bi-modally distributed with regard to size, and ranged from $0 \cdot 1$ to $0 \cdot 15$ and 0.4 to $0.6 \mathrm{~mm}$. When silver hake larvae were $c .7 \mathrm{~mm} L_{\mathrm{T}},>80 \%$ of the food items in their guts were $>0.6 \mathrm{~mm}$. In contrast, prey size increased more gradually with $L_{\mathrm{T}}$ for Atlantic cod larvae. For example, between 3 and $5 \mathrm{~mm} 60 \%$ of the numbers of items in their guts were $0 \cdot 15-0 \cdot 25 \mathrm{~mm}$ long. Likewise, while small prey items gradually diminished in importance in the diets of Atlantic cod larvae with increasing $L_{\mathrm{T}}$, even at the largest sizes larvae continued to feed on a broad range of developmental stages of copepods. In contrast, small prey items $(<0.4 \mathrm{~mm})$ virtually disappeared from the diet of silver hake by $5 \mathrm{~mm} L_{\mathrm{T}}$.

\section{NICHE WIDTH AND SELECTIVITY}

During November and December of 1992, silver hake and Atlantic cod larvae exhibited very different patterns in their feeding-niche widths $\left(I_{\mathrm{DB}}\right)$ with size, while the $I_{\mathrm{DB}}$ patterns for silver hake were generally similar during 1992 and 1998 (Fig. 5). During both years, the $I_{\mathrm{DB}}$ of silver hake larvae declined with $L_{\mathrm{T}}$, although the $I_{\mathrm{DB}}$ in 1998 was on average broader in 1992, but did not differ significantly between 3 and $11 \mathrm{~mm} L_{\mathrm{T}}$ where data overlapped. In 1998, $I_{\mathrm{DB}}$ declined from 0.30 at $2-3 \mathrm{~mm}$ to 0.05 at $6 \mathrm{~mm} L_{\mathrm{T}}$, and remained relatively constant and narrow until $10-11 \mathrm{~mm} L_{\mathrm{T}}$. The $I_{\mathrm{DB}}$ of silver hake in 1992 declined more rapidly from $c$. 0.24 at $3 \mathrm{~mm}$ (the smallest size class captured) to $<0.05$ at $4 \mathrm{~mm} L_{\mathrm{T}}$. From 4 to $13 \mathrm{~mm} L_{\mathrm{T}}, I_{\mathrm{DB}}$ remained narrow. There was a larger increase at $10-11 \mathrm{~mm}$ for silver hake examined from 1998 than from 1992. In contrast to the pattern of relatively narrow $I_{\mathrm{DB}}$ in silver hake (between 0.03 and $0 \cdot 08)$, the $I_{\mathrm{DB}}$ of Atlantic cod was on average broader $(0 \cdot 12$ to $0 \cdot 16)$, but the 


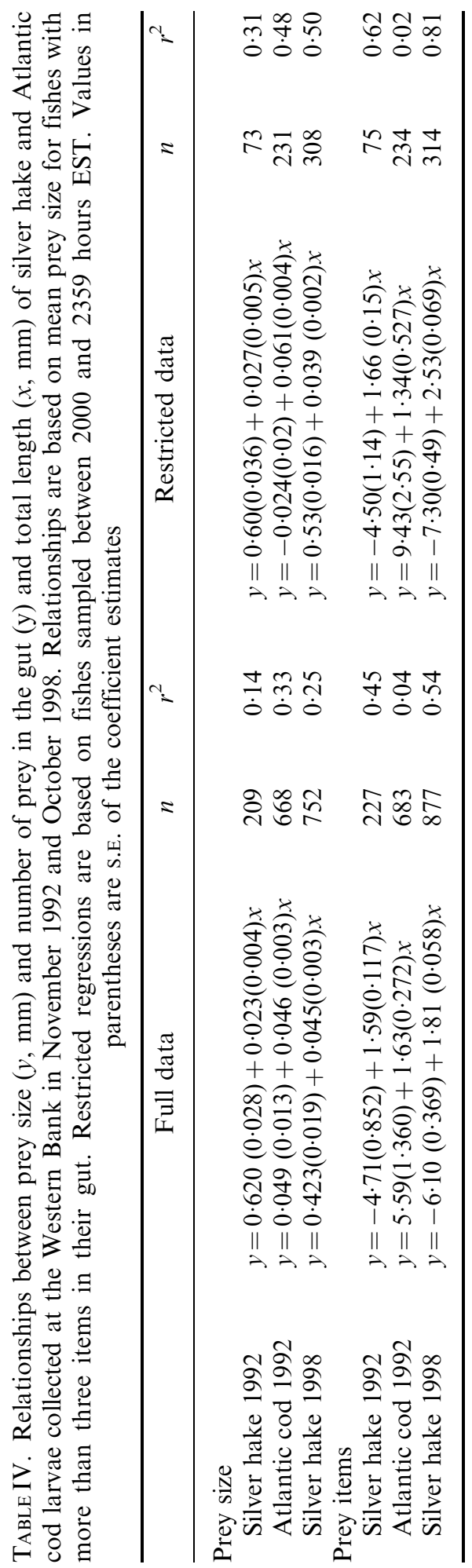




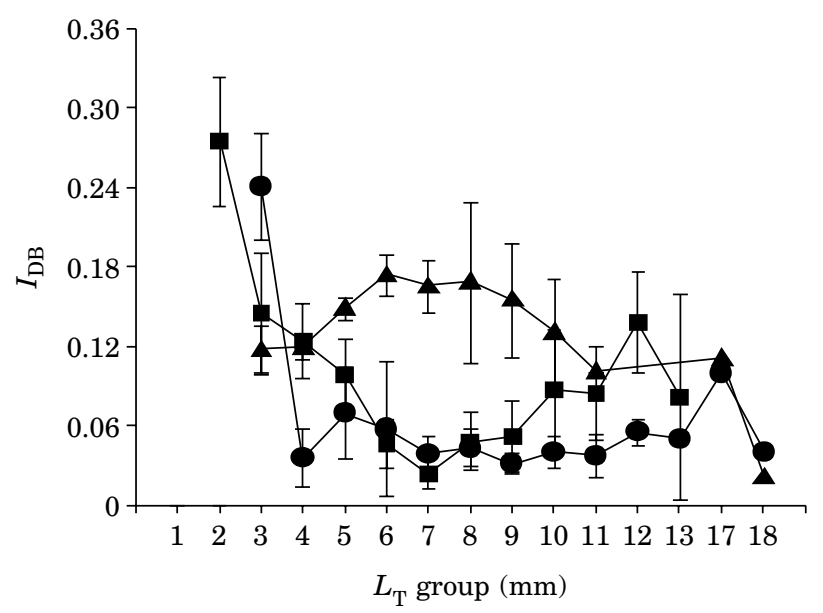

FIG. 5. Diet breadth index (niche width) over $1 \mathrm{~mm}$ total length groups from 1 to $18 \mathrm{~mm}$, estimated as the S.D. of the $\log _{10}$ of prey lengths (Pearre, 1986) for silver hake larvae collected in 1992 (ם) and 1998 (-) and Atlantic cod $(\boldsymbol{\Delta})$ collected in 1992. Only individuals of the given $L_{\mathrm{T}}$ class with three or more items in their guts were used in the analysis.

pattern was non-linear increasing in larvae from 3 to $6 \mathrm{~mm}$ before declining at larger $L_{\mathrm{T}}$ (Fig. 5).

Changes in larval feeding ecology could also be assessed using cumulative frequency distributions of developmental stages of copepod prey items [Fig. 6(a), (c), (e)] in diets, which showed large differences between the two fish species. In both years, silver hake larvae initially fed on small, early developmental stages, but also on later stages of copepods. With increasing $L_{\mathrm{T}}$, small prey items 'dropped out' of the diet and silver hake switched almost exclusively to larger prey, maintaining a narrow niche width. In contrast, Atlantic cod larvae exhibited the commonly assumed pattern of slowly replacing small items for large items with increasing body size. The cumulative frequency distributions clearly showed how the niche width could be a non-linear function of $L_{\mathrm{T}}$. As larvae began to feed both on large and small items, the variance in the mean size increased, and then declined as the switch to larger prey was completed.

The relative concentration of prey items in the water column revealed more about the difference in the feeding ecology of these two species. Values of $P_{\mathrm{i}}$ [Fig. 6(b), (d), (f)] illustrated considerable ontogenetic and temporal variability by silver hake larvae. During autumn 1998, silver hake were less selective than in winter 1992. In autumn, small silver hake larvae selected nauplii, but rapidly shifted at $5 \mathrm{~mm} L_{\mathrm{T}}$ to selecting copepodids. In the winter of 1992, silver hake were more selective, feeding mostly on adult copepods and late stage copepodids. In contrast, developing Atlantic cod larvae showed a gradual shift in selectivity from small nauplii to copepodids. The increase in selectivity by silver hake larvae, presumably following the autumn plankton bloom (McLaren \& Avendaño 1995), suggested that both the size-frequency distribution and species composition affected the diets of silver hake larvae. 

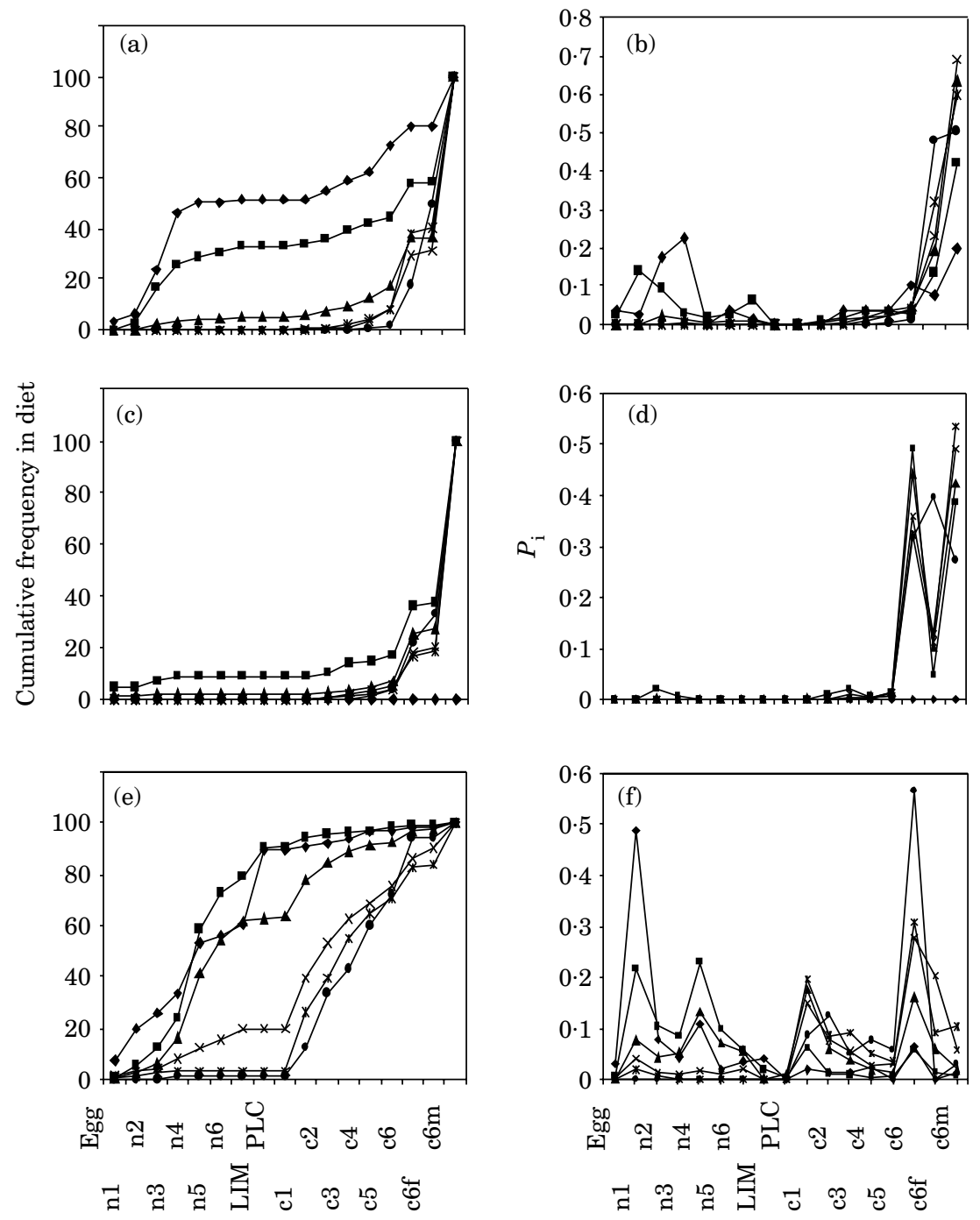

Developmental stage

FIG. 6. Cumulative frequency distribution of prey items in the diets of silver hake in (a) 1998 and (c) 1992 and (e) Atlantic cod in 1992, and Chesson's (1978) index of prey selectivity $\left(P_{\mathrm{i}}\right)$ for silver hake in (b) 1998 and (d) 1992 and (f) Atlantic cod in 1992 for 16 prey types of nominal size order (see Table II), in relation to fish total length $[<3(\bullet), 3$ to $5(\boldsymbol{\square}), 5$ to $7(\boldsymbol{\Delta}), 7$ to $9(\times), 9$ to $11(*)$ and $>11(\bullet) \mathrm{mm}]$.

\section{DISCUSSION}

Silver hake and Atlantic cod larvae exhibited distinctly different patterns of feeding selection and niche width. Silver hake larvae were highly selective with a relatively narrow and consistent feeding-niche width that changed sharply with increasing larval size. This differs from many studies that have shown that larval fish begin feeding on small prey items and gradually switch to larger 
prey items with increasing body size (body length and jaw length), but usually continue to include small prey items in their diets (McLaren \& Avendaño, 1995), resulting in a nearly constant feeding-niche width (log scale) through development (Pearre, 1986). The pattern observed for silver hake, however, is similar to that described for other merluccid hake species (de Chiechomski \& Weiss, 1974; Sumida \& Moser, 1980; Coates-Markle, 1982; Cass-Calay, 2003). Atlantic cod larvae exhibited the more usual feeding strategy, beginning to feed on naupliar stages and proceeding to larger and larger prey items as they grew. Over the same $L_{\mathrm{T}}$ classes as silver hake, however, the feeding niche width of Atlantic cod larvae was non-linear, inconsistent with the predictions of Pearre (1986), but similar to the findings for blue whiting Micromesistius poutassou (Risso) in the eastern Atlantic (Gonzalez-Quiros \& Anadon, 2001).

Despite the different feeding strategies, both silver hake and Atlantic cod fed on just a few of the total number of species present on the Western Bank. Only four species dominated each of their diets. The largest differences were related to the developmental stages that made up the diets of each species. Silver hake selected for larger, later developmental stages at much smaller $L_{\mathrm{T}}$ than Atlantic cod larvae. Based on the isometric relationships for silver hake and Atlantic cod, Atlantic cod larvae 5-7 $\mathrm{mm} L_{\mathrm{T}}$ had a jaw length of that of a 3-5 mm silver hake. Yet, the difference in jaw length at size is not entirely responsible for the differences in prey size. For example at a jaw length of $1 \mathrm{~mm}$, Atlantic cod fed on prey items of $c .0 .2 \mathrm{~mm}$ in width, while silver hake ate animals $>0.3 \mathrm{~mm}$ in width. This has clear implications for the differences in feeding ecology between the two species, creating the opportunity for silver hake to take advantage of the larger prey items not consumed by Atlantic cod, or other species that are spawned on the Western Bank.

Apparent selectivity for particular size classes or species may reflect the ease of capture, the apparent size (Luo et al., 1996), or energetic benefits to maximize energy intake and minimize energy expenditure (Werner \& Hall, 1974). The hypothesis that the selection exhibited by silver hake larvae, and the difference in selection between silver hake and Atlantic cod are passive responses to the presentation of food items cannot be rejected. The similarity in the diets, in terms of species selected and the pattern of selectivity of silver hake given the large (order of magnitude) differences in mean prey concentration between the two time periods, however, suggests that silver hake larvae feed on a very different part of the available prey spectrum than the co-occurring Atlantic cod larvae. At the same time, the fact that Atlantic cod feed on small prey items in a variety of habitats (Kane, 1984; Thompson \& Harrop 1991; Pepin \& Penney, 1997) suggests that regardless of availability, resulting selection by Atlantic cod is for smaller prey items.

Feeding theory also predicts that under food-limited conditions larval fishes should increase their feeding niche by ingesting a wider range of prey sizes or less nutritionally valuable prey (Werner \& Hall, 1974; Bartell, 1982). Despite an order of magnitude decline in prey abundance between October 1998 and December 1992, there was no evidence that silver hake larvae increased their feeding niche. In fact, silver hake exhibited a wider niche width over the 3$11 \mathrm{~mm} L_{\mathrm{T}}$ classes from autumn of 1998 as compared to winter of 1992. Moreover, niche width was narrower during winter of 1992 despite the fact that other 
prey species and developmental stages were available and used by Atlantic cod larvae, some of which (Pseudocalanus spp.) are known to store large quantities of energy rich lipids (Reiss et al., 1999). For example, while Pseudocalanus spp. increased slightly as a percentage of the diet (from 5 to $15 \%$ of gut content), Clausocalanus spp. increased from 12 to $43 \%$ of the diet of silver hake between October and December. Paracalanus parvus, another species that is believed to be easy to capture and nutritious (McLaren \& Avendaño, 1995) declined from 54 to $26 \%$ of the diet. In addition, no significant change in the mean prey size was observed between October and December as might be expected if food were limiting. One reason why an increase in the niche width may not have been observed was that two disparate time periods, with differing light or ancillary environmental conditions were compared. On the other hand, the remarkable similarity in diets of silver hake between the time periods, and the distinct and consistent pattern in feeding niche width with $L_{\mathrm{T}}$, suggests that silver hake may not be food limited on the Western Bank, and that other factors are critical in affecting their early life history.

On the Scotian Shelf, silver hake are common in the plankton from early July to December, while Atlantic cod are primarily present in early spring and early winter (Taggart et al., 1996; Jeffrey \& Taggart, 2000; Reiss et al., 2000). These two times represent different periods of the seasonal plankton cycle. During spring and early winter, the plankton is dominated by small copepods, either developmental stages or smaller species (McLaren et al., 1989), while the summer is dominated by later stages of larger copepods and a more developed plankton community. It is interesting to speculate that the differences in feeding ecology represent different adaptations to the plankton community during the peak spawning periods of these two species. Of course it is not possible to test such an hypothesis, although the observations that in almost all systems examined Merluccius spp. eat very large prey at small sizes lends some credibility to this hypothesis (de Chiechomski \& Weiss, 1974; Sumida \& Moser, 1980; CassCalay, 2003).

This paper is a GLOBEC Canada contribution. We thank the Captain and crew of the $C C G S$ Parizeau, for their help and dedication to our research programme. We also thank, C.T. Taggart, B. deYoung, G. Panteleev, P. Groenkjaer; A. Bochdansky, J. Jeffrey, A. Pickle and A. Vanderlaan, as well as W. Judge and D. Hazen for all their help in the field. S. Cass-Calay provided interesting and constructive comments on an earlier draft of this paper. This work was sponsored by the Natural Sciences and Engineering Research Council (NSERC) to the Canadian-GLOBEC Western Bank Program through grants to C. Taggart, I. McLaren and B. deYoung. Previous research conducted during the Ocean Production Enhancement Network (OPEN) was also supported by (NSERC) and was one of 11 Centres of Excellence. C. Reiss was a GLOBEC Canada Post Doctoral Fellow.

\section{References}

Bartell, S. M. (1982). Influence of prey abundance on size selective predation by bluegills. Canadian Journal of Fisheries and Aquatic Sciences 32, 1663-1670.

Cass-Calay, S. L. (2003). The feeding ecology of larval Pacific hake (Merluccius productus) in the California Current region: an updated approach using a combined OPC/ MOCNESS to estimate prey biovolume. Fisheries Oceanography 12, 34-48. 
Chesson, J. (1978). Measuring preference in selective predation. Ecology 59, 211-215.

de Chiechomski, J. D. \& Weiss, G. (1974). Studies on the feeding habits of larvae of hake (Merluccius hubbsi) and of the anchovy, Engraulis anchoias in the sea. Physis 33, 199-208

Coates-Markle, L. (1982). Larval and pelagic juvenile feeding ecology of three sympatric Scotian shelf hakes (Pisces: Gadidae). MSc Thesis, University of Guelph, Ontario, Canada.

Cushing, D. H. (1990). Plankton production and year class strength in fish populations: an update on the match/mis-match hypothesis. Advances in Marine Biology 26, 249-293.

Diaz, W. \& Evans, F. (1983). The reproduction and development of Microsetella norvegica (Boeck) (Copepod, Harpacticoida) in Northumberland coastal waters. Crustaceana 45, 113-130.

Fiksen, O., Utne, A. C. W., Aksnes, D. L., Eiane, K., Helvik, J. V. \& Sundby, S. (1998). Modelling the influence of light, turbulence and ontogeny on ingestion rates in larval cod and herring. Fisheries Oceanography 7, 355-363.

Frost, B. W. (1989). A taxonomy of the marine calanoid copepod genus Pseudocalanus. Canadian Journal of Zoology 67, 525-551.

Gonzalez-Quiros, R. \& Anadon, R. (2001). Diet breadth variability in larval blue whiting as a response to plankton size structure. Journal of Fish Biology 59, 1111-1125. doi: 10.1006/jfbi.2001.1724

Hilgruber, N., Kloppmann, M., Wahl, E. \& von Westernhagen, H. (1997). Feeding of larval blue whiting and Atlantic Mackerel: a comparison of foraging strategies. Journal of Fish Biology 51, 230-239.

Hinrichsen, H., Lehmann, A., Moellmann, C. \& Schmidt, J. (2003). Dependency of larval fish survival on retention/dispersion in food limited environments: the Baltic Sea as a case study. Fisheries Oceanography 12, 425-433.

Hunt von Herbing, I. H. \& Gallager, S. M. (2000). Foraging behavior in early Atlantic cod larvae (Gadus morhua) feeding on a protozoan (Balanion sp.) and a copepod nauplius (Pseudodiaptomus sp.). Marine Biology 136, 591-602.

Jeffrey, J. A. \& Taggart, C. T. (2000). Growth variation and water mass associations of larval silver hake (Merluccius bilinearis) on the Scotian Shelf. Canadian Journal of Fisheries and Aquatic Sciences 57, 1728-1738.

Kane, J. (1984). The feeding habits of co-occurring cod and haddock larvae from Georges Bank. Marine Ecology Progress Series 16, 9-20.

Lawson, T. J. \& Grice, G. D. (1970). The development stages of Centropages typicus Kroyer (Copepoda, Calanoida). Crustaceana 18, 187-208.

Luo, J., Brandt, S. B. \& Klebasko, M. J. (1996). Virtual reality of planktivores: a fish's perspective of prey selection. Marine Ecology Progress Series 140, 271-283.

Mayer, C. M. \& Wahl, D. H. (1997). The relationship between prey selectivity and growth and survival in a larval fish. Canadian Journal of Fisheries and Aquatic Sciences 54, 1504-1512.

McLaren, I. A. \& Avendaño, P. (1995). Prey field and diet of larval cod on Western Bank, Scotian Shelf. Canadian Journal of Fisheries and Aquatic Sciences 52, 448-463.

McLaren, I. A., Tremblay, M. J., Corkett, C. J. \& Roff, J. C. (1989). Copepod production on the Scotian shelf based on the life-history analyses and laboratory rearings. Canadian Journal of Fisheries and Aquatic Sciences 46, 560-583.

McLaren, I. A., Avendaño, P., Taggart, C. T. \& Lochmann, S. E. (1997). Feeding by larval cod in different water-masses on Western Bank, Scotian Shelf. Fisheries Oceanography 6, 250-265.

Munk, P. (1997). Prey size spectra and prey availability of larval and small juvenile cod. Journal of Fish Biology 51, 340-351.

Pearre, S. (1986). Ratio-based trophic niche breadths of fish, the Sheldon spectrum and the size efficiency hypothesis. Marine Ecology Progress Series 27, 299-314.

Pepin, P. \& Penney, R. W. (1997). Patterns of prey size and taxonomic composition in larval fish: are there general size-dependent models? Journal of Fish Biology 51, 84-100. 
Pepin, P. \& Penney, R. W. (2000). Feeding by a larval fish community: impact on zooplankton. Marine Ecology Progress Series 204, 199-212.

Reiss, C. S., McLaren, I. A. \& Avendaño, P. (1999). Utility of storage lipid volumes in inferring recent trophic history of copepods. Canadian Journal of Fisheries and Aquatic Sciences 56, 2444-2449.

Reiss, C. S., Panteleev, G. G., Taggart, C. T., Sheng, J. \& deYoung, B. (2000). Observations on larval fish transport and retention on the Scotian Shelf in relation to geostrophic circulation. Fisheries Oceanography 9, 195-213.

Reiss, C. S., Anis, A., Taggart, C. T., Dower, J. F. \& Ruddick, B. (2002). Relationships among vertically structured in situ measures of turbulence. Larval fish abundance and feeding success and copepods on Western bank, Scotian Shelf. Fisheries Oceanography 11, 156-174.

Reiss, C. S., McLaren, I. A. \& Avendaño, P. (2003). Horizontal and vertical distribution patterns, retention rates, and population dynamics of zooplankton on Western Bank, Scotian Shelf. Canadian Journal of Fisheries and Aquatic Sciences 60, $1229-1244$.

Sazhina, L. I. (1985). Naupliusy massovykh vidov pelagicheskikh kopepod Mirovogo okeana. Opredelitel. [Nauplii of widespread species of pelagic copepods of the World Ocean. An identification key.]. Kiev: Naukova Dumka.

Shirota, A. (1970). Studies of the mouth size of fish larvae. Bulletin of the Japanese Society of Fisheries Oceanography 36, 353-368.

Sumida, B. Y. \& Moser, H. G. (1980). Food and feeding of Pacific Hake Larvae, Merluccius productus, off southern California and northern Baja California. CalCOFI Reports 21, 161-167.

Taggart, C. T., Thompson, K. R., Maillet, G. R., Lochmann, S. E. \& Griffin, D. E. (1996). Abundance and distribution of larval cod (Gadus morhua) and zooplankton in a gyre-like water mass on the Scotian Shelf. In Proceedings of the International Workshop on Survival Strategies in Early Life Stages of Marine Resources (Watanabe, Y. Y. \& Oozecki, Y., eds), pp. 155-173. Rotterdam: A. Balkema Publishers.

Thompson, A. B. \& Harrop, R. T. (1991). Feeding dynamics of fish larvae of Copepoda in the western Irish Sea, with particular reference to cod Gadus morhua. Marine Ecology Progress Series 68, 213-223.

Werner, E. E. \& Hall, D. J. (1974). Optimal foraging and the selection of prey by the Bluegill sunfish (Lepomis macrochirus). Ecology 55, 1042-1054. 